Palimpsesto Vol. 10, $\mathrm{N}^{\mathrm{o}} 17$ (enero-junio, 2020): 99-109

Universidad de Santiago de Chile, ISSN 0718-5898

Rosana di Francesco

Universidad Nacional de Rosario

rodifran377@gmail.com

\title{
Cerdos\&Peces. Una revista para pensar la transgresión en la transición democrática en Argentina
}

\section{Cerdos\&Peces. A Magazine to Think about the Transgression in the Democratic Transition in Argentina}

\begin{abstract}
Resumen
El presente artículo parte de la hipótesis de que la revista Cerdos\&Peces (1984-2004), plataforma trasgresora de algunos sectores juveniles en la pos dictadura argentina, puede ser pensada como dispositivo de exposición (Rogers, 2019; Benjamín, 1989). Asimismo, se analizarán los modos en que la propuesta de la revista Cerdos\&Peces, desde el número 1 correspondiente a 1984 hasta el número 16 fechado en 1986, muestra la transgresión enunciativa durante la transición democrática en la Argentina. De este modo se indagará en los aspectos que se eligen exponer, así como también cuáles son las que se seleccionan para sobreexponer en el marco epocal de la transición democrática, focalizando en el under como plataforma transgresora.
\end{abstract}

Palabras claves: publicaciones periódicas, transición democrática, transgresión, underground.

\begin{abstract}
This article is created from the hypothesis that the magazine Cerdos\&Peces (1984-2004), which had a transgressive attitude with the youth sector after the Argentine dictatorship, can be considered as an exhibition device (Rogers, 2019; Benjamín, 1989). Also, there is an analysis about the ways in which the proposal of the magazine Cerdos\&Peces, from its number 1 in 1984 to its number 16 in 1986, shows the declarative transgression during the democratic transition in Argentina. In this way, there will be an inquiry in the aspects chosen to be exposed and, in the ones, chosen to be overexposed in the framework of the democratic transition, focusing on what is known as the under in the sense of a transgressive platform.
\end{abstract}

Keywords: periodicals, democratic transition, transgression, underground. 


\section{Introducción}

La importancia de Cerdos\&Peces (1984-2004) como revista radica en su circunscripción histórica dado que es una publicación que expresa una transgresión inhabitual en tiempos de posdictadura, abordando temáticas que escandalizaban a la sociedad media. Asimismo, dichas temáticas eran impugnadas por los periodistas y no reconocidas por la intelectualidad. Enrique Symns $^{1}$ fue el director de la revista antes mencionada durante los 59 números que conforman la publicación. Su salida no tenía una regularidad, sino que los números se editaron de manera casi caótica entre 1984 y 2004, dejando años enteros en que la revista no salía por diferentes motivos que se retomarán más adelante.

Cerdos\&Peces. La revista de este sitio inmundo, tal como señalaba su cintillo, fue una publicación que se desprendió del diario El Porteño (1982-1993) dirigido por Gabriel Levinas. En efecto, en un principio, Cerdos\&Peces formaba parte de ese diario, pero la transgresión que había seducido a Levinas, se tornó excesiva y la escisión radicó en la negativa de los editores, entre los que se encontraba el escritor argentino Miguel Briante, a publicar esos contenidos como parte del diario por no considerarlos periodísticos. Dichos contenidos atravesaban tópicos tales como: drogas, prostitución, sexo orgiástico, pedofilia, delincuencia, entre otros temas controversiales para esa época, fundamentalmente por el tono apologético que era transversal a todos los artículos, desplegando e instalando un estilo que fue el sello editorial de Symns en lo que se esbozaría como revista a partir de 1984, luego de la decisión de Levinas de separar el suplemento del diario, tal como se señaló.

El lugar físico donde funcionó la redacción de Cerdos\&Peces fue variando, sin embargo, la mayoría de los colaboradores recuerdan la calle Cochabamba al 700 en el barrio de Constitución de Buenos Aires. Asimismo, entre los variopintos colaboradores encontramos al escritor Osvaldo Baigorria, la dibujante Maitena, Vera Land (que luego se constituyó en la editora) los periodistas Ricardo Ragendorfer, Mariano del Mazo y Fernanda Simonetti, el artista plástico Jorge Gumier Meier, el cantante y letrista de los Redonditos de Ricota: El Indio Solari y la periodista y política Maria Eugenia Estenssoro, entre otros.

Esta publicación periódica fue una plataforma trasgresora de algunos sectores juveniles en la pos dictadura argentina y puede ser pensada como dispositivo de exposición, esto es, una arquitectura de aparición periódica que dispone en conjunto lo visible y lo legible (Rogers, 2019, p.12). La disidencia que caracterizó a los integrantes y colaboradores de Cerdos\&Peces se ubica en una zona de marginalidad que no es económica ni social, sino que cultiva la periferia como zona a explorar donde conviene exponer lo feo, lo malo, lo contario, lo disidente, lo que la sociedad media desechó o escondió bajo la alfombra.

\footnotetext{
${ }^{1}$ Enrique Symns nació en Lanús en 1946. Es un periodista y narrador considerado de los más influyentes de la cultura urbana y el under porteño. Fue monologuista de la banda Patricio Rey y sus redonditos de Ricota en la década del 80 y director de Cerdos\&Peces durante los 20 años en que la revista se editó de forma discontinuada. Además, escribió en El Porteño, Fin de Siglo, Satiricón y fue colaborador en los diarios Sur y Clarín. Como escritor, editó varios libros de cuentos y crónicas periodísticas que rescatan sus propias experiencias en la noche porteña siguiendo los avatares del under junto con los músicos de Los Piojos, La Bersuit Vergarabat y Los Caballeros de la Quema. Sin embargo, a su regreso de Chile donde formó parte del diario El Mercurio, en el año 2001, editó la novela autobiográfica que convulsionó al mundillo del rock: El Señor de los Venenos. En dicha obra, Symns revela cuestiones personales que había vivido juntos con los integrantes de Redondos.
} 
Cerdos\&Peces construye un relato estetizado de la marginalidad constituyendo una propuesta a tono con las expectativas de descubrimientos que algunos sectores de la juventud detentaban. Ese residuo es lo que busca poner en valor Symns como director de la revista para recuperar los espacios avasallados, como por ejemplo la calle.

Si la transición se nutre de dualidad y de movimiento, como señala Masiello, la revista rescatará lo residual y lo marginal transitando por pasajes propios de la época donde nada es tranquilo. Más bien todo es oscilatorio, pendular y efímero. Asimismo, Symns seleccionará, a partir de la época en que se configura la publicación, los contenidos más transgresores, aquellas temáticas que calarían en lo más hondo de lo considerado tabú para la sociedad media. Indagaremos en este trabajo qué elementos se eligen exponer, así como también cuáles son las que se seleccionan para sobreexponer y cuáles son las que deciden evitar en este marco epocal ${ }^{2}$. Dada la relevancia de esta publicación en su contexto histórico, los primeros apartados se detendrán en la relevancia de transgresión en la revista durante la transición democrática, mientras que los dos últimos apartados analizarán específicamente los modos de exposición.

\section{La transición democrática como marco de la génesis de Cerdos\&Peces.}

El período de la transición democrática en Argentina sirve para ubicarnos temporalmente con el objetivo de entender la selección de contenidos que hicieron los productores de la revista, así como también la distribución de espacios, y también las decisiones que tomaron dichos integrantes frente a los componentes de la revista. El período denominado transición democrática abarca, siguiendo la línea de José Luis De Diego $(2002)^{3}$ la franja temporal que va de 1983 a 1986. Se constituyó en una etapa fundacional en la que se discutieron, parafraseando a de Diego, los presupuestos ideológicos de la década anterior. La "primavera alfonsinista" tuvo su apogeo en 1985, pero se resquebrajó ya en 1986. La ley de Punto Final y la suspensión de los Juicios a los genocidas fueron factores determinantes que precipitaron la frustración de los habitantes. Siguiendo la línea de De Diego, la transición democrática en la Argentina abría un ciclo de esperanza y desilusión que repetía la experiencia frustrada de muchos jóvenes militantes de la década de 1970.

Si la transición democrática fue un ciclo de esperanza y desilusión como destacamos siguiendo la estela de De Diego, Cerdos\&Peces, a la que colocamos temporalmente en ese marco, tomó partido por la decepción, por lo feo, por lo malo, constituyendo un lema que ofició de manifiesto de la revista: "Cuanto peor, mejor". Symns eligió exponer la pedofilia desde la perspectiva de la apología (C\&P, $\left.\mathrm{n}^{\mathrm{0}} 3,1984\right) .{ }^{4}$ Asimismo eligió titular: "Violadoras violadas" una

\footnotetext{
${ }^{2}$ En este sentido, Geraldine Rogers señala: "Pensar las publicaciones periódicas como construcciones destinadas a mostrar (poner a la vista, dar a leer) implica en primer lugar atender a la dimensión performativa que puede o no coincidir con las declaraciones explícitas. Abre la pregunta acerca de qué y cómo en ellas se expone, se subexpone o se sobreexpone, y lleva a considerar la creación de revistas como modo de intervenir en el reparto de lo visible y lo legible en la esfera pública y en el reparto de bienes simbólicos" (2019, p.14).

3 "La democracia en nuestro país trajo aparejada la esperanza de muchos sectores de la sociedad, fundamentalmente sectores progresistas. Es claro que luego de la derrota de la guerra de Malvinas, el proceso de transición hacia la democracia estuvo plagado de sobredimensionadas expectativas. Claramente no hay un pacto de transición y entonces el paso del Régimen autoritario y sus horrores a la ansiada democracia arrastra o prolonga elementos que van a continuar durante el gobierno del Dr. Raúl Alfonsín”. (De Diego, 2000 p. 22).

${ }^{4}$ A partir de aquí de mencionará así a la revista.
} 
nota donde se afirmaba: "Muchas mujeres desean ser violadas y hasta eligen a su violador" (C\&P, n², 1984). En el mismo número se entrevistó a "Claudio", a quien se presentaba como el mentor del gran robo al Banco de Galicia en 1976. En esa entrevista, el protagonista era un ladrón a quien se mostraba como tal desde una perspectiva nuevamente apologética, desde el discurso directo que oficiaba de titular: "Yo si quiero, me robo ese banco", frase que reafirmaba en la nota el entrevistado con total desparpajo y provocando, al amparo de una publicación en la que sentía cierto respaldo (C\&P, $\left.\mathrm{n}^{\circ} 2,1984\right)$. Del mismo modo, y en el número antes citado, apareció una nota al pie del artículo titulado: "Somos todos maricones". La nota, firmada por el artista plástico Jorge Gumier Meier, relacionaba a la revista con personajes de la cultura que aún estaban en el exilio y que ocupaban un lugar marginal respecto de la cultura hegemónica, como era el caso del escritor y militante Néstor Perlongher que fuera luego también entrevistado por Cerdos\&Peces. Dicho pie de página invitaba "A toda persona que quiera comunicarse con el Movimiento Gay de Liberación dirigirse personalmente o por carta a Cerdos\&Peces Cochabamba 726 Capital." $\left(\mathrm{C} \& \mathrm{P}, \mathrm{n}^{\circ} 2,1984\right)$.

La débil democracia argentina, tras siete años de horror producido por la última dictadura militar, no estaba preparada para las provocaciones del iconoclasta Symns. Solo algunos sectores de la juventud validarían su aporte transgresor.

\section{La tribu iconoclasta}

Cerdos\&Peces publicó su primer número como revista independiente en abril de 1984 . Dicho número comenzaba con un editorial que funcionaría como manifiesto de la propuesta de Symns. El título de dicho artículo era: "Sacarse las etiquetas". Allí Symns afirmaba: "Nuestra identidad yace sepultada bajo los rótulos con los que una sociedad autoritaria pretende reprimir y contener experiencias que, supuestamente, desestructuran el orden comunitario". (C\&P, $\left.\mathrm{n}^{\mathrm{o}} 1,1984\right)$. Fueron cuatro los números que se lograron poner en circulación en ese año (correspondientes a los meses de abril, mayo, junio y julio), y el tono transgresor se planteó, como vimos, desde la primera página del primer número. La falta de continuidad en Cerdos\&Peces se debió, entre otros motivos, al rasgo efímero de una época en la que todo fluía vertiginosamente.

El lector de Cerdos\&Peces siempre fue una tribu lectora de los contenidos que eran rechazados por sectores conservadores de la moral pública. Por este motivo, Symns debió enfrentar varias causas por alteración de valores morales, y debió comparecer en 1986, ante un organismo que aún seguía vigente y se llamaba Moralidad, dependiente de Policía Federal, por el contenido transgresor de la mayoría de las notas que lograba publicar. ${ }^{5}$ De este modo me interesa destacar que, en 1986 solo tres fueron los números que lograron publicarse, o sea uno menos que en 1984 cuando la revista recién había surgido. Además, señalo en esta línea de la discontinuidad como rasgo de la época transicional, que en 1985 la revista directamente no logró editar ni un solo número. Asimismo, es relevante que, Cerdos\&Peces logró una cierta continuidad, llegando a publicar nueve números continuos (del octavo número al decimosexto), en el año 1987; el

\footnotetext{
5 "Hay una contra reunida en torno a la revista Cerdos\&Peces, que la cerraron por sobrecarga de procesos penales, cuyo director, Enrique Symns (Un tipo bárbaro, tenés que conocerlo) aún soporta." Néstor Perlongher Carta a Osvaldo Baigorria. Baigorria, Osvaldo. Cerdos\&Porteños. Blatt\&Ríos, 2014.
} 
decimoséptimo número que correspondería a ese año, se saltea por cábala, es decir que los integrantes del staff prefieren omitir ese número por considerarlo desgraciado.

Este recuento sugiere un cambio en las condiciones de circulación de los discursos con el correr del tiempo: si la transgresión que esgrimía la revista en sus enunciaciones había sido desestabilizante en el inicio de la democracia, transcurridos unos años, la revista obtenía apoyo de algunos sectores asociados a franjas juveniles que se habían conformado con espíritu tribal alrededor de su propuesta.

Es posible que muchos lectores inmersos en el descreimiento se sintieran representados por el exceso de transgresión de la publicación de Symns. Esas tribus juveniles que transitaban el desencanto desde la Guerra de Malvinas, reactivaron su decepción por las decisiones tomadas durante el gobierno del Dr. Raúl Alfonsín. Algunas de esas medidas tales como la suspensión de los Juicios, la Ley de Punto Final, la Ley de Obediencia Debida, promovidas por dicho gobierno, pavimentaron la sensación de frustración de algunos sectores de la juventud. El espíritu de contrariedad incluía la amenaza de los alzamientos carapintadas, y el denominado Plan Austral que sumía a la población nuevamente en la zozobra económica. Esas tribus inmersas en la decepción se vieron representadas por el exceso de transgresión de la revista de Symns. El espíritu de la rebeldía juvenil de la pos dictadura se figuraba en un grito desajustado que impugnó a viva voz todo lo que la dictadura militar había impuesto. Aunque Cerdos\&Peces siempre se mantuvo desligada de proclamas partidarias, es posible pensar que representó una postura política aglutinando a la franja no future.

El paradigma dictatorial que se puede sintetizar en: tradición, familia y propiedad tuvo una línea de continuidad aun durante el gobierno del Dr. Alfonsín, considerado por la prensa hegemónica como el paladín de la democracia. Sin embargo, dicho presidente fue considerado por Symns como: "El gran enemigo de la revista" 6 . Tal hecho se demuestra con el cierre de Cerdos\&Peces ocurrido en abril de 1987. En ocasión de la visita de Juan Pablo II, algunos lectores de la publicación se manifestaron contra la presencia papal y fueron reprimidos en la Plaza de los dos Congresos. El editorial del undécimo número destacaba: "Esto es lo alarmante, la violencia estatal en un estado de derecho como única opción para controlar las situaciones que, supuestamente, vienen a desestructurar el orden establecido" (C\&P, n¹1, 1987). Cabe aclarar que el editorial mencionado fue el único en la historia de la publicación que llevó la firma de otra persona que no fuera Symns. En este caso: Fernando Almirón.

El objetivo de la publicación había sido siempre la expresión transgresiva que desafiara a la sociedad media a través del culto, admitido por Symns, por el periodismo gonzo ${ }^{7}$ vernáculo y una inspiración abrevada de Hunter Thompson. Se puede pensar a Cerdos\&Peces como una publicación que horadó tanto el propio universo alternativo de la época como a la moral media, constituyéndose en una tribu para otra tribu; sus lectores. Cerdos\&Peces puso en tensión ese doble objetivo de atacar a la moral media, y a la vez a todo lo alternativo o contracultural, y de este modo, se constituyó en un muro que separaba y religaba a la vez.

La transgresión fue la herramienta poderosa de la que se valió Symns para enfrentar caóticamente a los que consideraba enemigos: casi todos. En un principio, los postulados buscaban provocar a la iglesia, el estado, la familia. Sin embargo, sobre el fin de la década,

${ }^{6}$ Mendoza, Juan (2015). Entrevista a Enrique Symns publicada como prólogo de Cerdos\&Peces. Lo mejor, Buenos Aires: El Cuenco de Plata.

${ }^{7}$ El "periodismo gonzo" es periodismo subjetivo. Esa es la clave mayor de los escritos gonzo. Contrario a lo que enseña el manual, la idea es ser lo más personal posible, solo así la experiencia trasmitida será real, en eso consiste la veracidad del periodismo de estos relatos. 
coincidiendo con una cierta continuidad de la aparición física de la revista ${ }^{8}$, las provocaciones también tuvieron como objetivo a aquellos que habían formado parte de la contracultura y de la génesis de la propia revista. Symns había sido parte de los Redonditos de Ricota, así como el Indio Solari había escrito en Cerdos\&Peces, pero Symns se mostraba decepcionado por el incipiente ingreso de dicha banda al mainstream.

Symns buscaba a través de la transgresión, desmontar hipocresía, resquebrajar lo que catalogaba como la moral pacata de la medianía. Su decepción ahora tenía como blanco también a quienes habían sido sus amigos y colaboradores, a su propio origen. No abandonó la provocación a las instituciones, pero sumó a quienes fueron parte del proyecto, pero se alejaron siguiendo los avatares de la época. Symns apareció adherido casi anacrónicamente a esa pos dictadura en la que se inició, aunque estuviera ya en el fin de la década.

\section{Modos de exposición de Cerdos\&Peces en la transición democrática. El under como plataforma transgresora.}

En Argentina, el under fue una expresión propia de los ochentas y estuvo asociada a los mismos espacios que la contracultura, aunque no tuvo los mismos objetivos. Entendemos a la contracultura como la línea editorial que sostuvieron revistas como El Expreso Imaginario durante los setentas. La contracultura en el país acomodaba los postulados de la Generación Beat, surgida en 1948 en la Universidad de Columbia en E.E. U.U., a las necesidades de un país que pasaba de la dictadura de Juan Carlos Onganía a la "primavera camporista" y detentaba ideales utópicos de transformación social a través de las letras de rock de grupos tales como Almendra, liderado por Luis Alberto Spinetta. En cambio, el under, según sostiene Fernando García, "asesina a la contracultura y usa el crimen para mandarle un mensaje mafioso a la cultura más abarcativa" (2017, p.37). Si el under es un término poco preciso, tal como sostiene Pipo Lernoud, la palabra "reviente" representa casi cabalmente lo que se constituía a su alrededor (2016).

Siguiendo la línea de García, la fealdad del under y el culto nihilista que se configuraban en él, le remarcaban a la contracultura su final, producido por el vaciamiento de contenido contra que había subsumido a la cultura oficial. En este marco se esboza Cerdos\&Peces, en tanto y en cuanto el under es la insignia de los ochentas, entre formaciones rockeras como Patricio Rey y sus Redonditos de Ricota, Sumo y espacios simbólicos del under de Buenos Aires tales como Café Einstein o Cemento. Dado que Cerdos\&Peces nunca sostuvo una postura política partidaria afín al alfonsinismo progresista, como así tampoco se adhirió al peronismo ni a ninguna línea de nacionalismo, y al mismo tiempo manifestaba un descreimiento de la izquierda y solamente sostenía postulados desde el anarco individualismo profesado fundamentalmente por Symns, la revista fue bandera representativa de todos aquellos sectores que se alineaban en la decepción y la criminalización de la política. De esa forma, Cerdos\&Peces se constituyó en factor de aglutinamiento de los "posmodernos" que anticipaban los noventas. Asimismo, Cerdos\&Peces puso en escena y le dio un lugar central a prácticas culturales que emergían de lo subterráneo, del espíritu under al que referimos. El modo en que desplegó dichas prácticas pone en juego la tensión entre mostrar, no mostrar o mostrar en exceso.

${ }^{8}$ Cerdos\&Peces logra los 12 números en los años 1987 y 1990. 
En materia de decisiones editoriales para montar ${ }^{9}$ Cerdos\&Peces actuó siempre como un colectivo transgresor y creativo conformando una tribu que apeló a otra tribu: sus lectores, como sistema de legitimación. Ese público lector, la porción de la juventud que se configuró en la tribu lectora de la revista, se había despegado ya de la contracultura y mostraba un estado de ánimo propio de la época transicional en la que construye su materialidad la revista: un estado de ánimo alterado y agazapado. Una tribu cultora del rasgo que la constituyó: una tribu efímera.

El Indio Solari, cantante y frontman de la banda argentina Patricio Rey y sus Redonditos de Ricota, colaborador de Cerdos\&Peces, edita en 1986 una letra titulada "Ya nadie va a escuchar tu remera", que forma parte de un disco clave para dicha banda: Oktubre. En algunos de sus versos Solari destaca: "Esto es efímero/ Ahora efímero/ ¡Como corre el tiempo! / Tic... Tac efímero/ ¡Un último secuestro no! / ¡El de tu estado de ánimo, no! / Tu aliento vas a proteger/ En este día y cada día. / Luces efímeras".

Ese estado de ánimo agazapado y alerta se constituye alrededor de un dispositivo represivo que no se terminaba de desinstalar. Por eso, las decisiones que Symns toma para lograr su fin transgresor resultan poco eficaces en tanto se consolida la democracia. En los primeros años del gobierno de Alfonsín, Cerdos\&Peces contribuyó en el proceso de denuncia y visibilización de la violencia policial remanente de la dictadura. De este modo, los artículos sobre razzias en los bares, así como las encuestas a los detenidos ilegales promovieron la derogación de los edictos policiales y la averiguación de antecedentes funcionando como germen del reconocimiento de prácticas ilegales de continuidades represivas en el interior de las fuerzas policiales, aun cuando no se había acuñado el término gatillo fácil.

Si como afirmamos en párrafos anteriores, Cerdos\&Peces construye su materialidad en la pos dictadura, es relevante destacar en los aspectos materiales lo que Francine Masiello (2012) llama "estrategias de resistencia" llevadas adelante por el rock y otras performances artísticas propias de la época. Y vinculado con esto, las prácticas que surgieron en espacios marginales y la intervención de los intelectuales desde la década del 70, donde la figura del subalterno estimuló un discurso contra hegemónico (Masiello, 2012). Masiello recuenta, en esta línea, los argumentos de Néstor García Canclini (2011) quien revela lo problemática que se presenta la construcción de un discurso contra hegemónico dado el escepticismo propio de la desilusión de la lucha popular. Aquí, el sujeto marginal, antes identificado con formas populistas de resistencia, fue expulsado de la escena de la decisión intelectual.

Cerdos\&Peces se constituyó efectivamente en lo que su cintillo prometía: La revista de este sitio inmundo. Sin embargo, la publicación de Symns, hace legible lo que muchos también pensaban, mascullaban y, por supuesto, llevaban adelante en las sombras. En el segundo número de la revista correspondiente a 1984, Symns editorializaba: "Lo importante es transgredir con astucia”. Claramente el dispositivo represor no se había desactivado y, pese a la bandera cerdopeneana ${ }^{10}$ de la transgresión en clave cultura rock, Symns advertía en este editorial que era necesario hacerlo, pero al mismo tiempo, preservarse. Pareciera acertado lo que el director de la revista proponía, dado que en el mismo editorial abordaba, sin eufemismos, temas sensibles para la pacateria de la sociedad media: divorcio y aborto.

\footnotetext{
${ }^{9}$ De acuerdo con Rogers, montar una revista implica "construir diferencias cuantitativas y cualitativas, hacer una selección de lo que se muestra y cómo se lo expone, organizar un número determinado de recorridos por el índice, los títulos de secciones, las ilustraciones. Es organizar un sistema productor de discontinuidades y diferencias, 'sentidos' (u orientaciones) y 'comunicaciones' entre los subespacios incluidos en ella” (2019, p.21).

${ }^{10}$ Expresión utilizada por Vera Land en entrevista informal que se obtuvo en 2016.
} 
En un artículo que figura en el interior del mismo número de la revista, el aborto es tratado como "el delito que causa muerte de muchas jóvenes" y también como el gran dilema de los médicos que reciben en los hospitales casos que, según la ley, debieran ser denunciados como delito.

El editorial correspondiente al mismo segundo número de la revista se titulaba: "Quiénes son los criminales?". En el cuerpo de este editorial, y mediante preguntas retóricas dirigidas a un lector interpelado, Symns ofició de frontman que buscaba despertar conciencias anestesiadas y atemorizadas por los años de plomo, pero que al mismo tiempo se veían representadas en la enunciación de Symns. El emblemático director de Cerdos\&Peces reflexionaba como si estuviera en la misma vereda de un bar imaginario al que concurrían sus lectores devotos. "Una sociedad como la nuestra puede matar y dejar morir personas con la excusa de una Guerra, pero le prohíbe al individuo elegir el destino del ser que él mismo gestó. Por este motivo casi por cualquier otro, es imprescindible aprender a transgredir con astucia”.

En la línea de la preservación a la que refería el editorial, la revista aborda en este número la problemática de los edictos policiales vigentes que causaban, entre otras cosas, la detención de menores, replicando la metodología siniestra de la aun cercana dictadura. En el mismo número, una nota firmada por el propio Symns y titulada "La Policía", daba cuenta del rechazo que se tenía por esa institución. En esa misma nota, opinaban entre otros, el Juez Zaffaroni, el político Néstor Vicente, el actor Miguel Ángel Sola y el músico Pappo.

Todas estas notas, así como las decisiones editoriales permiten identificar el modo en que Cerdos\&Peces expuso y puso en valor la opinión de autoridades o figuras referenciales masculinas legitimadas en ciertos ámbitos progresistas. Dichos entrevistados coincidían en que la calle había sido recuperada, así como también convenían en que la policía no gozaba de la simpatía de nadie y estaba desprestigiada. Hacer visible la enmascarada represión fue una transgresión necesaria para alertar a las tribus en el adverso contexto.

\section{Cerdos\&Peces. El almacén de la transgresión.}

El sexo y el uso de drogas eran los principales contenidos sobreexpuestos tanto en lo que respecta a la visualidad de la revista, dada la proliferación de imágenes, como a los modos de abordarlos. Se exponía sexo con niños, violaciones, sexo con muertos, sexo orgiástico. Por su parte, las drogas no eran el vehículo de nada en particular, ni se utilizaba ningún eufemismo para referirse a su uso, sino que se las asociaba con la calle, con la juntada, con los amigos, con la tribu que eran ellos y que era su público.

Los integrantes de la revista no eran periodistas consagrados y mucho menos intelectuales legitimados. Cabe interrogarse, pues, acerca del sistema que legitimaría este tipo de publicación. Resulta oportuno pensar aquí Cerdos\&Peces como un híbrido que seleccionaba una agenda para operar y para convertirse en un dispositivo transgresor.

Así, en el quinto número de 1986, la tapa mostraba a una nena desnuda. Esto causó estupor hasta en la propia tribu. Sin embargo, la selección de la transgresión se valía de estos artilugios para provocar. Años más tarde, en el documental que se estrenara en BAFICI 2018 dirigido por Agustina Paz Frontera con el título de Este sitio inmundo (2018) esa nena, hoy devenida mujer, naturalizaba su intervención en esa tapa contextualizándola en época: su padre, 
amigo de Symns y colaborador de la revista, habría sacado esa foto y la protagonista refiere haberse divertido.

Si el nacimiento de la revista como soporte masivo de lectura fue afín al auge de grandes arquitecturas donde la ciudad y sus habitantes miraban y devenían a la vez objetos de exposición, en la línea de lo planteado por Benjamín (1989), los grandes temas tabúes de la sociedad argentina de la pos dictadura eran expuestos como en un almacén perverso, provocador y transgresivo en las imágenes de la revista y en los contenidos periodísticos y culturales.

En el tercer número de 1984, un artículo citaba a la revista canadiense Body Politic. El artículo se tituló: "Apología del delito" y su subtítulo anunciaba claramente y sin eufemismos lo que el almacén de Symns quería desplegar: Pedofilia Homosexual. Dos palabras que escandalizarían a cualquiera que no formara parte de la tribu disidente. En el artículo se presentaban varios casos como el de Simón, profesor de primaria, que consideraba que los niños no eran románticos y que eso lo excitaba. También aparecía el caso de Peter que declaraba que la edad que más le despertaba deseo sexual es la franja que va de los 12 a los 14 años. En el mismo número, un artículo se titula: "Los gays responden". En esa nota las preguntas rondaban sobre el rol de la Iglesia, en tanto mostrar a la homosexualidad como enfermedad. Del mismo modo, se sostiene que la moral atenta contra la naturaleza, por lo menos, según está concebida en esa actualidad.

En el décimo tercer número de 1987, el entrevistado fue el escritor Néstor Perlongher. En dicho reportaje las preguntas giraban en torno a la intensidad como el gran valor de la generación a la que pertenecían tanto el entrevistado como el entrevistador. Ante la reflexión, en tanto pregunta, de Symns: "Quizás sea necesario buscar nuevas formas de expresarnos", Perlongher, destacaba la transgresión que "tiende a reproducir el código dominante, cuando alguien dice "estamos haciendo apología del delito" está tomando como referente el código de la ley dominante" (1987, p.23). Resulta interesante esta intervención de Perlongher en tanto la eficacia de los objetivos de la enunciación de Symns. La desenfrenada búsqueda por diferenciarse del discurso hegemónico podría convertirse en una encerrona. La transgresión excesiva podría derivar en una réplica del orden que se intenta desafiar.

\section{Conclusiones}

Si el underground fue la expresión del reviente durante el periodo de transición en Argentina y Cerdos\&Peces se inscribió en esa época, lo sobreexpuesto de la publicación desplegó lo que la sociedad media intentaba esconder, todo lo que la medianía sostuvo para encajar en el paradigma dictatorial. Cerdos\&Peces provocó, desde su disrupción, con temas que la sociedad buscó esconder afanosamente. Temas tales como las drogas, la locura, la delincuencia, la marginalidad, la noche y la calle, las disidencias y la desmesura sexual. Todos estos temas eran abordados desde el exceso que desestabilizaba. Cerdos\&Peces expuso la droga y sobreexpuso un uso excesivo del consumo.

Esta publicación periódica permanentemente expuso y sobreexpuso alternando estos modos con el propósito de excederse en su enunciación, resta preguntarse qué subexpuso. Si la revista de Symns expuso la molestia de una sociedad atravesada por el paradigma dictatorial, y el resultado de una juventud decepcionada que adoptó el cinismo como forma de impugnar lo 
sucedido en la guerra de Malvinas y en las desilusiones, posteriores, seguramente lo que no expuso, lo que escondió lo que subexpuso, tenga que ver con una solución que no despejaría.

La transgresión excesiva resulta en ocasiones pintoresca, pero difícil de sostener en el tiempo. Cuando los avatares políticos cambian el rumbo, la transgresión puede no solo perder eficacia sino convertirse en un discurso funcional al orden que se desea impugnar. Cerdos\&Peces pudo haber representado algo pintoresco y hasta atrapante para una tribu juvenil deseosa de poder expresarse sin censura, pero es necesario repensar si esa enunciación resultó tal como se la plantearon sus integrantes, si se pudo actualizar con los avatares políticos y sociales de las diferentes épocas, y en este sentido cabe retomar la transgresión vinculada a los limites, planteada por Michel Foucault (1963). Si la transgresión necesitaría del límite. ¿Qué pasa cuando esos límites se corren? La revista pudo dar cuenta de esos corrimientos para reformular su propuesta en tanto el objetivo transgredible ya no estaba. Va de suyo que la propuesta de Symns atrajo a los jóvenes que crecieron en el horror de la dictadura y sus mandatos de censura, como así también que causó escozor en las capas medias que ideológicamente seguían adhiriendo al modelo dictatorial, por lo menos, en cuanto a las temáticas con las que la revista buscaba escandalizar. La transgresión excesiva fue el modo que usó Symns en la revista para desmontar una hegemonía creando una hegemonía propia a partir de la apología de los tópicos antes mencionados, aun sabiendo que esa estrategia tal vez no se pudiera sostener. Si los límites se corren, la transgresión planteada puede perder efectividad.

El editor, Symns, continúo subrayando el exceso del uso de cocaína y continúo tratando de escandalizar a la sociedad con imágenes explícitas de sexo, pero en los noventas, el gobierno de Carlos Menem superaba esas provocaciones. La cocaína y el sexo orgiástico eran el tema de agenda setting ${ }^{11}$ en el renombrado caso Coppola y la medianía a la que Cerdos\&Peces buscaba escandalizar, seguía los avatares de dicho affaire por televisión abierta. El uso desenfrenado de droga unido al sexo con menores fue, asimismo, el eje del femicidio de María Soledad Morales, la adolescente que fuera víctima de la mafia de los caudillos poderosos en la provincia de Catamarca en 1990.

De esta manera, Cerdos\&Peces operó de faro iniciático de una tribu de desangelados del sistema en la época transicional, pero no supo o no quiso ponerse a tono con los nuevos tiempos en los que el exceso de transgresión como la sobreexposición de las temáticas mencionadas, resultó funcional a un discurso al que terminó adherida. Como una caricatura del exceso de los ochentas, Cerdos\&Peces quedó anclada a una época oscilante que había tomado ya un rumbo. Los estados de ánimo fueron cambiando y la revista no pudo dar cuenta de esas modificaciones intentando sostener la transgresión como modo de expresión en coyunturas que hicieron que esa estrategia pierda efectividad.

${ }^{11}$ Concepto de Maxwell Mc Combsen McCOMBS, M. (1985), (v. o. 1975) "La comunicación de masas en las campañas políticas: información, gratificación y persuasión" en MORAGAS, M. de (eds). Sociología de la Comunicación de Masas. Estructura, funciones y efectos, Gustavo Gili, S.A., Barcelona. 


\section{Referencias Bibliográficas}

Baigorria, Osvaldo. (2014). Cerdos\&Porteños (1984-1987), Buenos Aires: Blatt\&Ríos.

Benjamin, Walter. (1989). "La obra de arte en la época de su reproductividad técnica" [1935]. Discursos interrumpidos I. Buenos Aires, Taurus, pp. 15-57.

Baudelaire, Charles. (2013) El pintor de la vida moderna. Buenos Aires, Taurus.

Cerdos\&Peces, números 1-59.

De Diego, José Luis. (2000). Campo intelectual y campo literario en la Argentina (1970- 1986). Tesis de doctorado. Universidad Nacional de La Plata. Facultad de Humanidades y Ciencias de la Educación.Disponibleenhttp://www.fuentesmemoria.fahce.unlp. edu.ar/tesis/te.150/te.150.pdf.

Didi-Huberman, Georges. (2006). Ante el tiempo. Historia del arte y anacronismo de las imágenes. Buenos Aires, Adriana Hidalgo. . (2014). Pueblos expuestos, pueblos figurantes. Buenos Aires: Manantial.

El Porteño. (1984). número 40.

Foucault, Michel. (1963). Prefacio a la transgresión, Buenos Aires: Editorial Trivial en Hommage a George Bataille, Critique, 195,196, agosto, septiembre. Traducción: Axel Gasquet.

García, Fernando. (2017) Crimen y vanguardia. El caso Schoklender y el surgimiento del underground en Buenos Aires, Buenos Aires: Editorial Paidós.

Masiello, Francine. (2012). El arte de la transición, Buenos Aires: Grupo Editorial Norma.

Mc Combs, Maxwell. (1985). "La comunicación de masas en las campañas políticas: información, gratificación y persuasión" en MORAGAS, M. de (eds). Sociología de la Comunicación de Masas. Estructura, funciones y efectos, Gustavo Gili, S.A., Barcelona.

Mendoza, Juan. (2015). Cerdos\&Peces. Lo mejor, Buenos Aires: El Cuenco de Plata. Perlongher, Néstor. (1987). “Lo que buscamos es intensidad” Cerdos\&Peces N¹3. Rogers, Geraldine. (2019). "Las publicaciones periódicas como dispositivos de exposición”, EN: Delgado, Verónica; Rogers, Geraldine, coordinadoras. Revistas, archivo y exposición: Publicaciones periódicas argentinas del siglo XX. La Plata: Universidad Nacional de La Plata. Facultad de Humanidades y Ciencias de la Educación.

Reguillo, Rosanna. (2000). Emergencia de culturas juveniles. Estrategias del desencanto. Buenos Aires, Grupo Editorial Norma.

Williams, Raymond. (1980). Marxismo y Literatura, Barcelona, Editorial Península. 